\title{
Cronkhite-Canada Syndrome with a Major Duodenal Papillary Adenocarcinoma
}

\author{
Yuta Fuyuno ${ }^{1}$, Tomohiko Moriyama ${ }^{1}$, Yoshiteru Kumagae ${ }^{2}$ and Motohiro Esaki ${ }^{1}$
}

Key words: Cronkhite-Canada syndrome, adenocarcinoma of the major duodenal papilla

(Intern Med 56: 2805-2807, 2017)

(DOI: 10.2169/internalmedicine.8858-17)
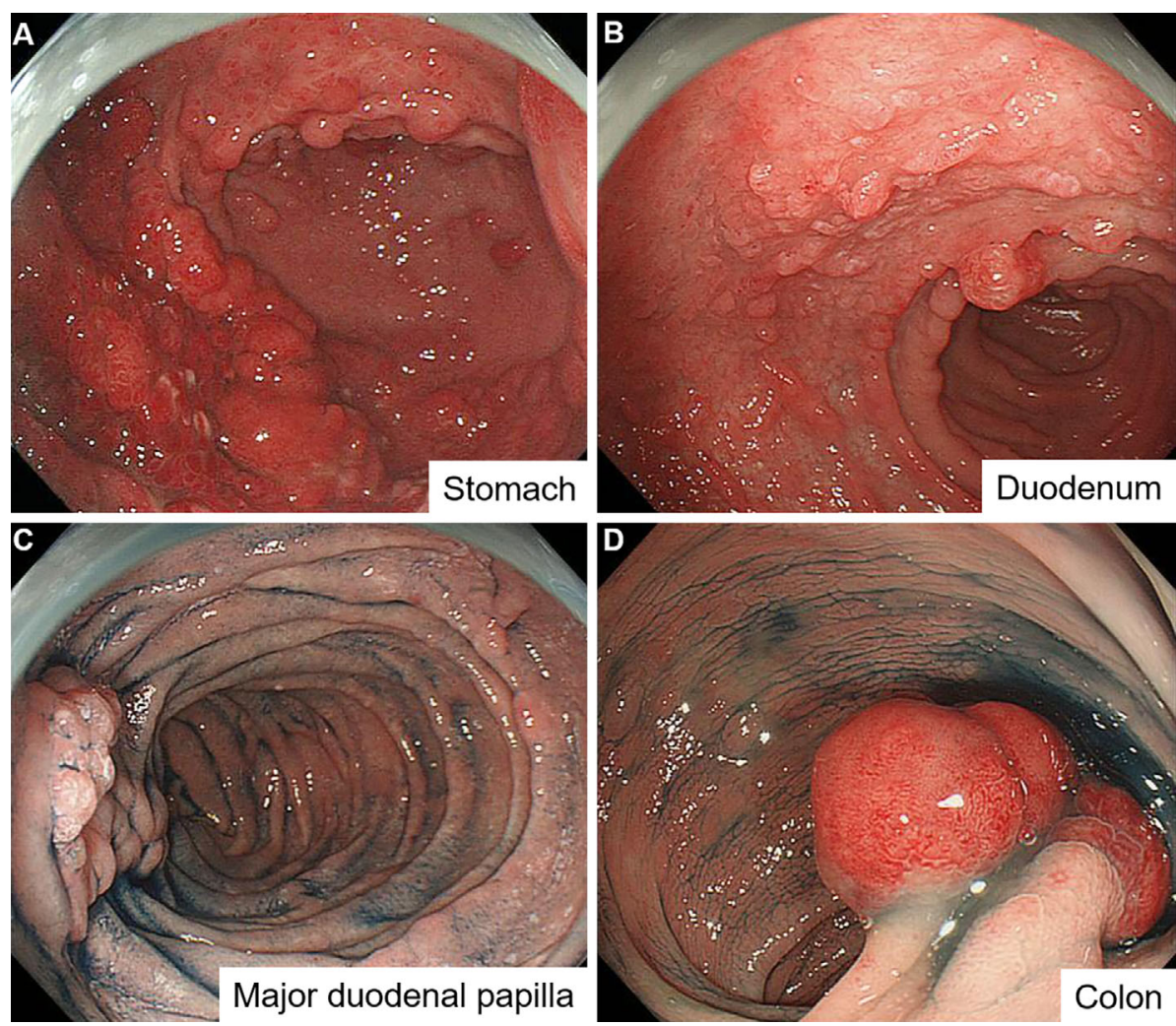

Picture 1.

Cronkhite-Canada syndrome (CCS) is known to have a malignant potential (1); this is the first report of adenocarcinoma arising from the major duodenal papilla of a patient with CCS. The patient was a 66-year-old Japanese man who had been suffering from cacogeusia, alopecia, onychodystrophy and cutaneous hyperpigmentation for 2 years was referred to our hospital. Esophagogastroduodenoscopy and colonoscopy showed numerous reddish polyps in the stomach, the duodenum including major duodenal papilla, and the colon (Picture 1). A biopsy specimen showed inflammation with edematous stroma and a hyperplastic foveolar epithelium. He was diagnosed to have CCS based on his physical and endoscopic findings. Although most of the gastroduodenal polyps disappeared after 6 months of treatment with prednisolone (initial dose, $60 \mathrm{mg} /$ day; maintenance dose, $5 \mathrm{mg} /$ day), the major duodenal papilla remained enlarged (Picture 2). Pylorus-preserving pancreatoduodenectomy was performed. A histological examination revealed

${ }^{1}$ Department of Medicine and Clinical Science, Graduate School of Medical Sciences, Kyushu University, Japan and ${ }^{2}$ Department of Anatomic Pathology, Graduate School of Medical Sciences, Kyushu University, Japan

Received: January 16, 2017; Accepted: March 6, 2017; Advance Publication by J-STAGE: September 15, 2017

Correspondence to Dr. Yuta Fuyuno, yfuyuno@intmed2.med.kyushu-u.ac.jp 

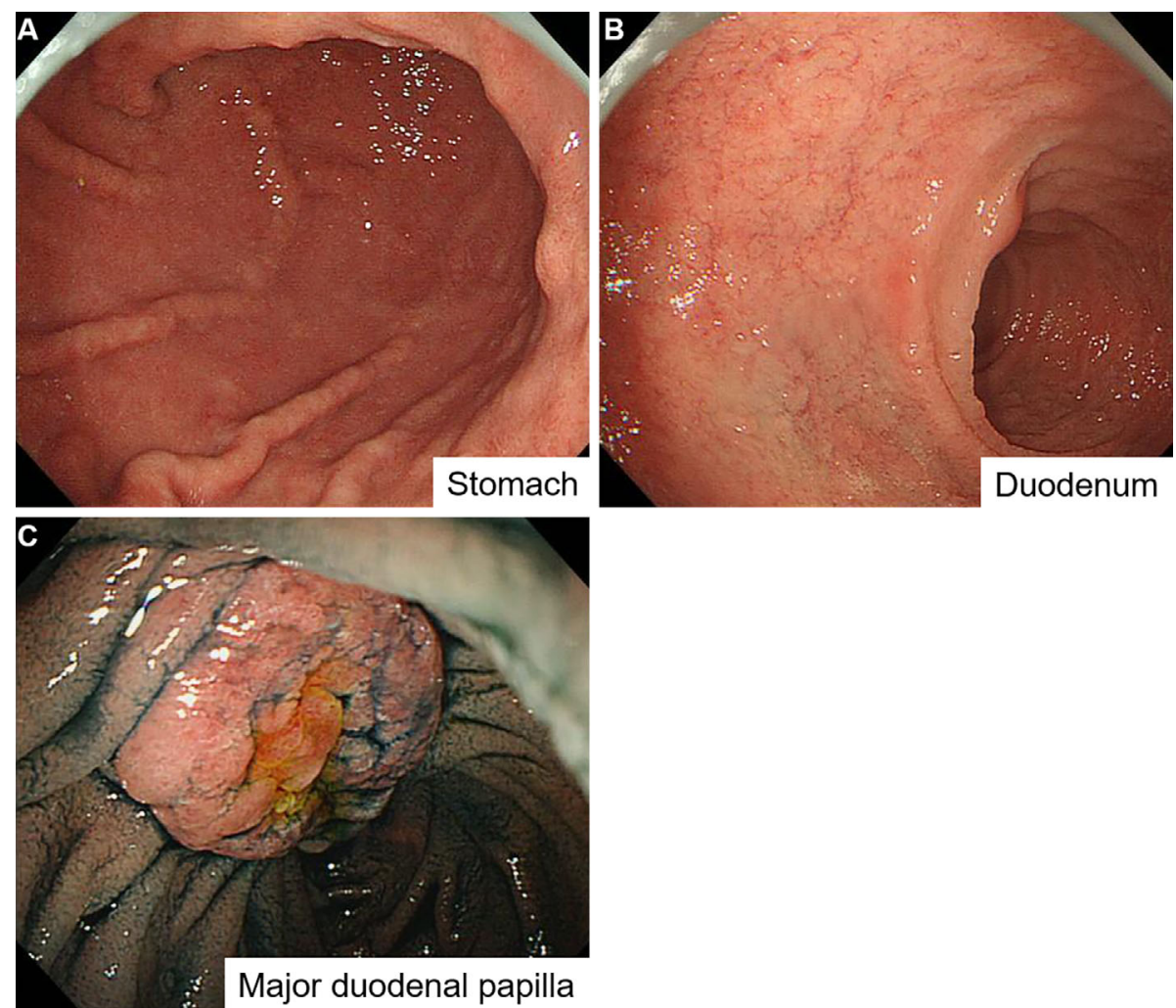

Picture 2.

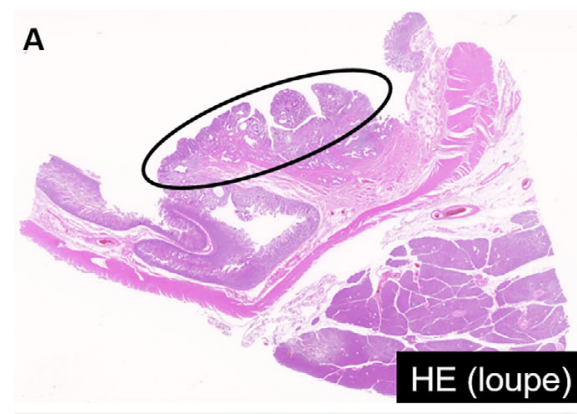

。
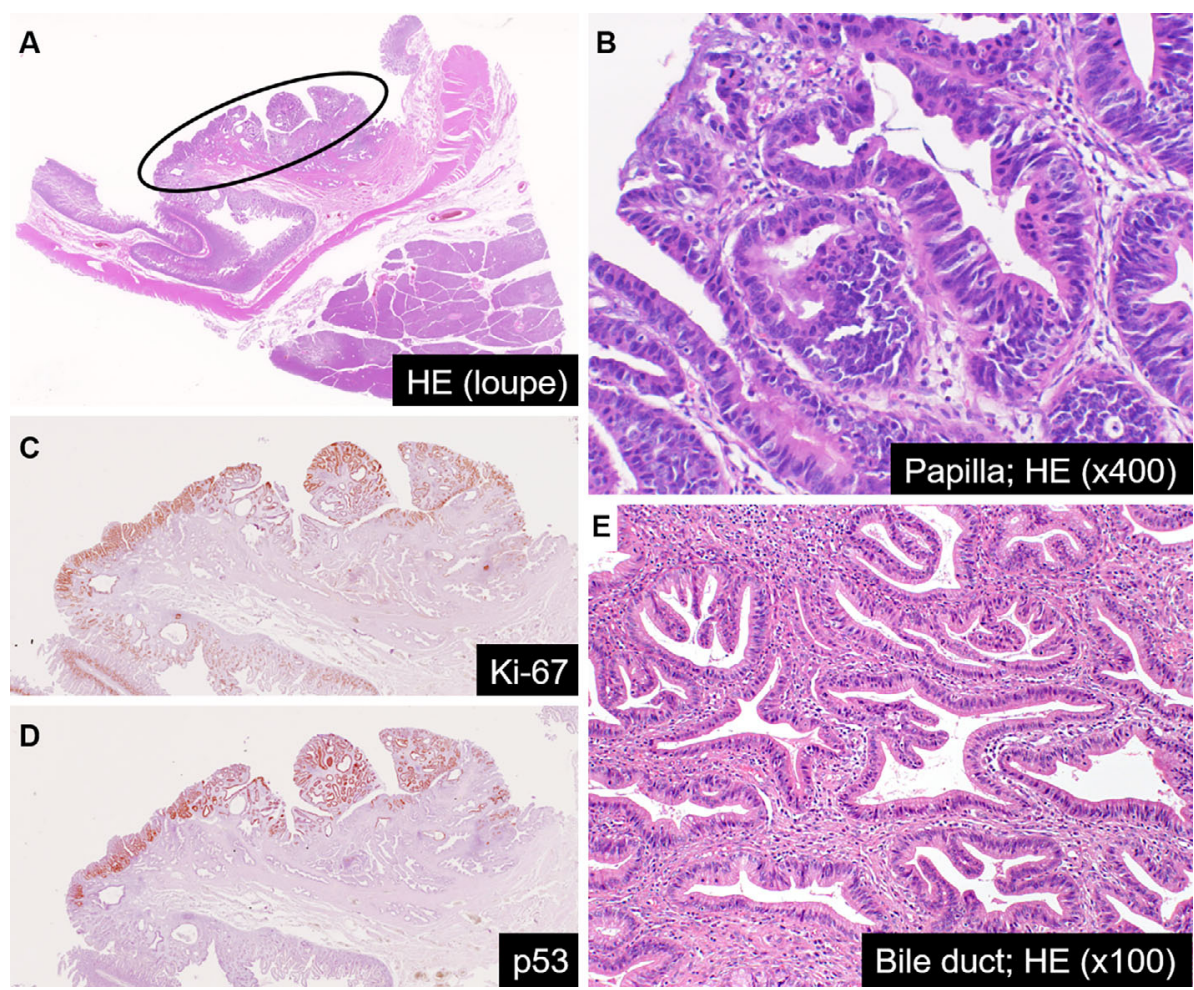

Picture 3.

that the resected tumor was well-differentiated adenocarcinoma in situ without stromal invasion, and showed that the dysplastic epithelial cells had spread into the bile duct (pT1N0M0) (Picture 3).
The authors state that they have no Conflict of Interest (COI).

\section{Reference}

1. Watanabe C, Komoto S, Tomita K, et al. Endoscopic and clinical 
evaluation of treatment and prognosis of Cronkhite-Canada syndrome: a Japanese nationwide survey. J Gastroenterol 51: 327-336, 2016.
The Internal Medicine is an Open Access article distributed under the Creative Commons Attribution-NonCommercial-NoDerivatives 4.0 International License. To view the details of this license, please visit (https://creativecommons.org/licenses/ by-nc-nd/4.0/).

(C) 2017 The Japanese Society of Internal Medicine Intern Med 56: 2805-2807, 2017 